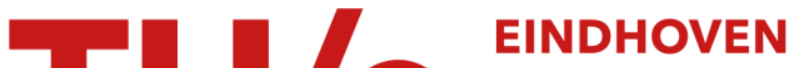 UNIVERSITY OF TECHNOLOGY
}

\section{The initial instability of cemented and non-cemented femoral stems fixated with a bone grafting technique}

\section{Citation for published version (APA):}

Schreurs, B. W., Huiskes, H. W. J., \& Slooff, T. J. J. H. (1994). The initial instability of cemented and noncemented femoral stems fixated with a bone grafting technique. Clinical Materials, 16(2), 105-110. https://doi.org/10.1016/0267-6605(94)90104-X

DOI:

10.1016/0267-6605(94)90104-X

Document status and date:

Published: 01/01/1994

\section{Document Version:}

Publisher's PDF, also known as Version of Record (includes final page, issue and volume numbers)

\section{Please check the document version of this publication:}

- A submitted manuscript is the version of the article upon submission and before peer-review. There can be important differences between the submitted version and the official published version of record. People interested in the research are advised to contact the author for the final version of the publication, or visit the $\mathrm{DOI}$ to the publisher's website.

- The final author version and the galley proof are versions of the publication after peer review.

- The final published version features the final layout of the paper including the volume, issue and page numbers.

Link to publication

\section{General rights}

Copyright and moral rights for the publications made accessible in the public portal are retained by the authors and/or other copyright owners and it is a condition of accessing publications that users recognise and abide by the legal requirements associated with these rights.

- Users may download and print one copy of any publication from the public portal for the purpose of private study or research.

- You may not further distribute the material or use it for any profit-making activity or commercial gain

- You may freely distribute the URL identifying the publication in the public portal.

If the publication is distributed under the terms of Article 25fa of the Dutch Copyright Act, indicated by the "Taverne" license above, please follow below link for the End User Agreement:

www.tue.nl/taverne

Take down policy

If you believe that this document breaches copyright please contact us at:

openaccess@tue.nl

providing details and we will investigate your claim. 


\title{
The Initial Stability of Cemented and Non-cemented Femoral Stems Fixated with a Bone Grafting Technique
}

\author{
B.W. Schreurs, R. Huiskes* \& T.J.J.H. Slooff \\ Biomechanics Section, Institute of Orthopaedics, University of Nijmegen, PO Box 9101, 6500 HB Nijmegen, \\ The Netherlands
}

(Received 7 September 1993; sent for revision 6 October 1993; accepted 17 December 1993)

\begin{abstract}
To reconstruct intramedullary bone stock in revision surgery of failed total hip arthroplasties, a method was developed using impacted trabecular bone grafts. In an in vitro model with femora of the goat, the initial stabilities of both cemented and non-cemented hydroxylapatite-coated stems in this graft construction were determined in a loading experiment immediately after insertion. Displacements of stems relative to bone were determined with roentgen-stereophotogrammetric analysis. The most important movements were axial rotations (cemented stems up to $2 \cdot 1^{\circ}$, non-cemented stems up to $6.8^{\circ}$ ) and subsidence (cemented stems up to $0.5 \mathrm{~mm}$, non-cemented stems up to $2.9 \mathrm{~mm}$ ). These motions were caused predominantly by slippage and compaction of grafts. It is concluded that the cemented stems reach a better initial stability, probably by cement penetrating in the graft layer. For non-cemented stems used in combination with the grafting technique developed, additional means to guarantee initial stability are needed.
\end{abstract}

\section{INTRODUCTION}

Although results of total hip arthroplasties are impressive, the number of revisions is growing. Generally speaking, about $10 \%$ of arthroplasties must be revised within 10 years post-operatively. The main rcasons for revision are ascptic loosening and infection. ${ }^{1}$ Problems often encourtered on the femoral side are the loss of bone stock and sclerosis of the endosteal wall. The bone stock loss is caused by the loosening process itself and by the removal of bone cement during these revisions. ${ }^{24}$

Several grafting techniques, with different types of bone grafts, have been described for cases of severe femoral bone loss. ${ }^{59}$ In our department, bone grafting techniques are successfully used in severe cases of acetabular bone loss. ${ }^{10}$ After cleaning and reaming, trabecular bone chips are

*To whom correspondence should be addressed. impacted (marcellized) to reconstruct the acetabulum. A cemented cup is then implanted. In 1988 we developed a method for using a similar technique for the femoral side. Using special equipment, an intramedullary reconstruction of the endosteal wall is created with bone grafts. Within this rcconstruction a stem is fixed. An in vitro study was carried out to determine the immediate post-operative relative motions of stems under loading fixated with this grafting technique, using roentgen-stereophotogrammetric analysis (RSA) according to Selvik. ${ }^{11}$ Revisions of failed THA are performed by cemented and non-cemented techniques. Hence, both cemented and non-cemented stems were investigated.

\section{MATERIALS AND METHODS}

Eight freshly frozen goat femora were used in 
combination with freshly frozen trabecular bone grafts of sternal origin. The maximal storage period, at $-20^{\circ} \mathrm{C}$, was 6 months. After thawing, the femoral head was resected using an oscillating saw. Next the femoral canal was opened using hand reamers (diameter $8-13 \mathrm{~mm}$ ). The femur of the goat contains trabecular bone only in the proximal part. With the reamers, only this trabecular bone in the proximal femur was removed; next, canal lavage was performed. Then an appropriately sized AlloPro bone cement plug was screwed on a metal rod (cemented stems rod diameter 8 or $10 \mathrm{~mm}$, non-cemented stems rod diameter $10 \mathrm{~mm}$ ).

This construction was introduced in the medullary canal. The space between this rod and the cortical bone $(2-4 \mathrm{~mm})$ was filled with grafts in a retrograde fashion. The trabecular bone grafts were chip-like and obtained from the sternum by using rongeurs. By using a specially developed set of instruments, the grafts were impacted (Fig. 1). In this way, an intramedullary wall of bone chips was created. After completion of the filling process, the central metal rod was unscrewed and removed, leaving a central cavity surrounded by bone grafts. Within this central cavity a stem was inserted.

In four cases, cemented prostheses were placed (Mathys type 2.30.702, Fig. 2(a)). Bone cement (Sulfix) was injected in retrograde fashion using a cement syringe, $225( \pm 15) \mathrm{s}$ after adding the monomer to the powder, at a room temperature of 22.5 $( \pm 1.5)^{\circ} \mathrm{C}$. The prosthesis was placed $285( \pm 15) \mathrm{s}$ after starting the mixing process. In the other four femora, non-cemented titanium prostheses, fully coated with hydroxylapatite (thickness $40-60 \mu \mathrm{m}$ ), were inserted following the normal clinical procedures (Fig. 2(b)). The prosthesis was manufactured by Osteonics and the coating was applied by CAM BV. ${ }^{12}$ Both types of prostheses had a tantalum pellet attached to the tip prior to insertion, contained in an acrylic strut glued to the metal.

The bones were wrapped in physiological salinedrenched gauze bandages and kept for $24 \mathrm{~h}$ at $4^{\circ} \mathrm{C}$. They were then resected just above the distal condyles and partly embedded in PMMA. Tantalum pellets were attached proximally and distally to the medial and lateral sides of the cortical bone. At each location three pellets were placed. Hence, four sets of three pellets defined the position of the bone (Fig. 3). Two small PMMA rods, containing three tantalum pellets

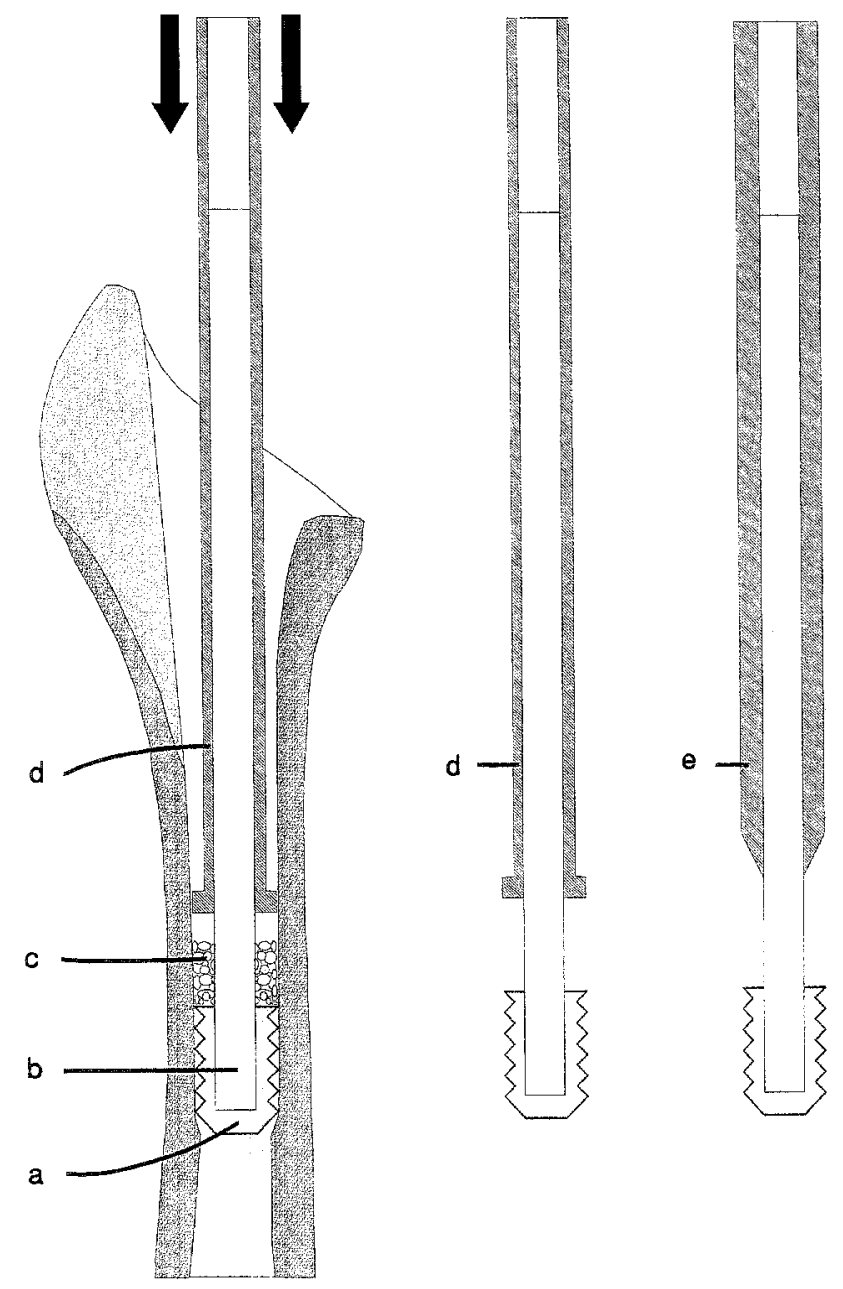

Fig. 1. Schematic drawing of the graft impaction technique using a special set of instruments. A bone cement plug (a) is screwed on a metal rod (b) and introduced into the canal. The space between this metal rod and the cortical bone is filled with trabecular bone grafts (c). These grafts are impacted using metal lubes sliding over the central rod. Different types of tubes are used for axial (d) and radial (e) impaction of the grafts.

each, were glued to the medial and lateral aspects of the lower neck of the prostheses. Hence, two sets of three pellets proximally and one single pellet distally defined the position of the prosthesis (Fig. 3).

The implanted prostheses were then loaded in an MTS testing machine. Relative to the vertical position, the femora were tilted $15^{\circ}$ in the lateral direction and endorotated $45^{\circ}$, in order to obtain a physiological load on the femoral head. ${ }^{13}$ The load was applied stepwise from zero to 200,500 and $800( \pm 10) \mathrm{N}$. After each loading step, the load was kept constant for 10 min (Fig. 4). Before loading, 1 and $10 \mathrm{~min}$ after each load was applied, and again 10 min after final unloading, roentgenstereograms were taken (Fig. 4). These were measured on an Aristomat digitizer, and the threedimensional pellet positions at all selected time 


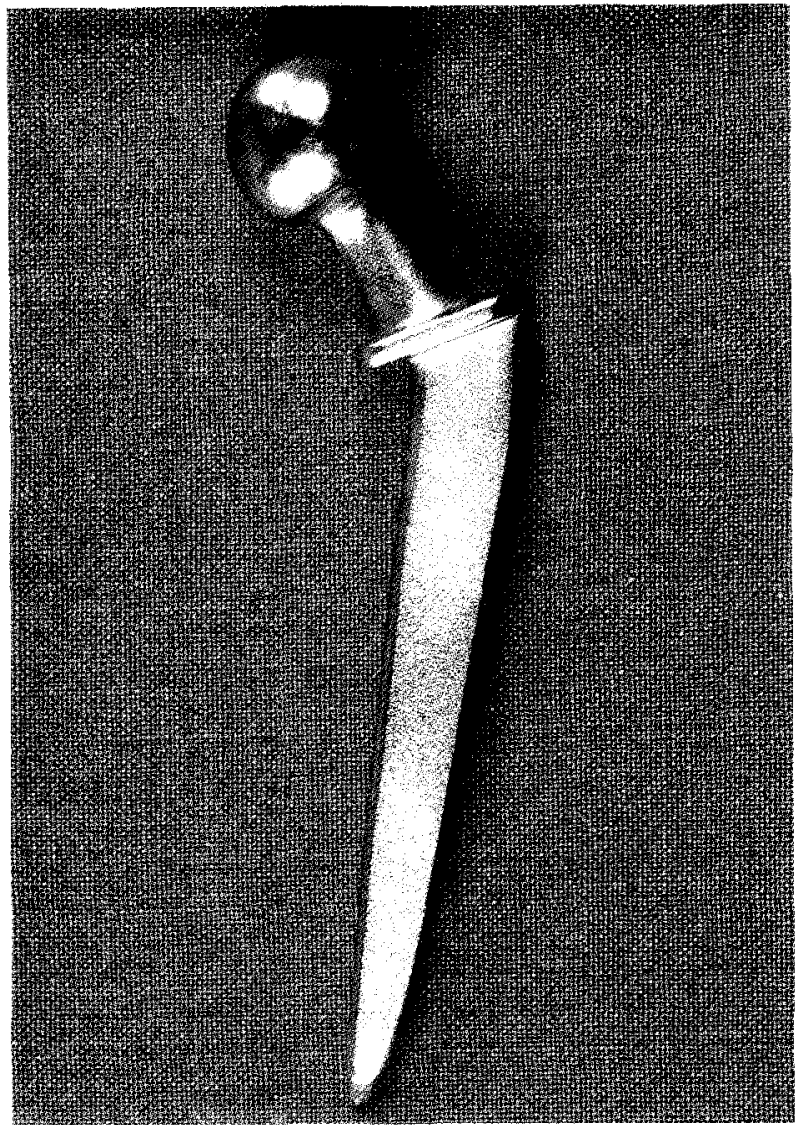

Fig. 2(a). The prosthesis used in combination with bone cement.

periods during the loading cyclc were determined with the RSA computer system. To increase the accuracy of the results, all roentgen films were measured 5 times and the results averaged. Using the second part of the RSA computer system, based on rigid body kinematics, and the subsequent pellet position data, the three-dimensional displacements of the prosthesis relative to the bone were evaluated. ${ }^{11}$ This evaluation produced relative translations along the $x$-axis (lateralmedial translation), $y$-axis (axial translation, i.e. subsidence) and z-axis (anterior-posterior translation) of a particular base point of the prosthesis, and rotations about the $x$-axis (rotation in the sagittal plane), $y$-axis (horizontal plane) and $z$-axis (frontal plane). The coordinate axes are depicted in Fig. 3. In order to obtain a good assessment of the relative displacements, the translations were calculated for three base points in the prosthesis, one the pellet under the distal tip, and the other two pellets at the medial and lateral proximal sets. In order to neutralize the effects of bone deformations due to loading (i.e. bending), all the results were evaluated using four different combinations of the four bone-pellet sets.

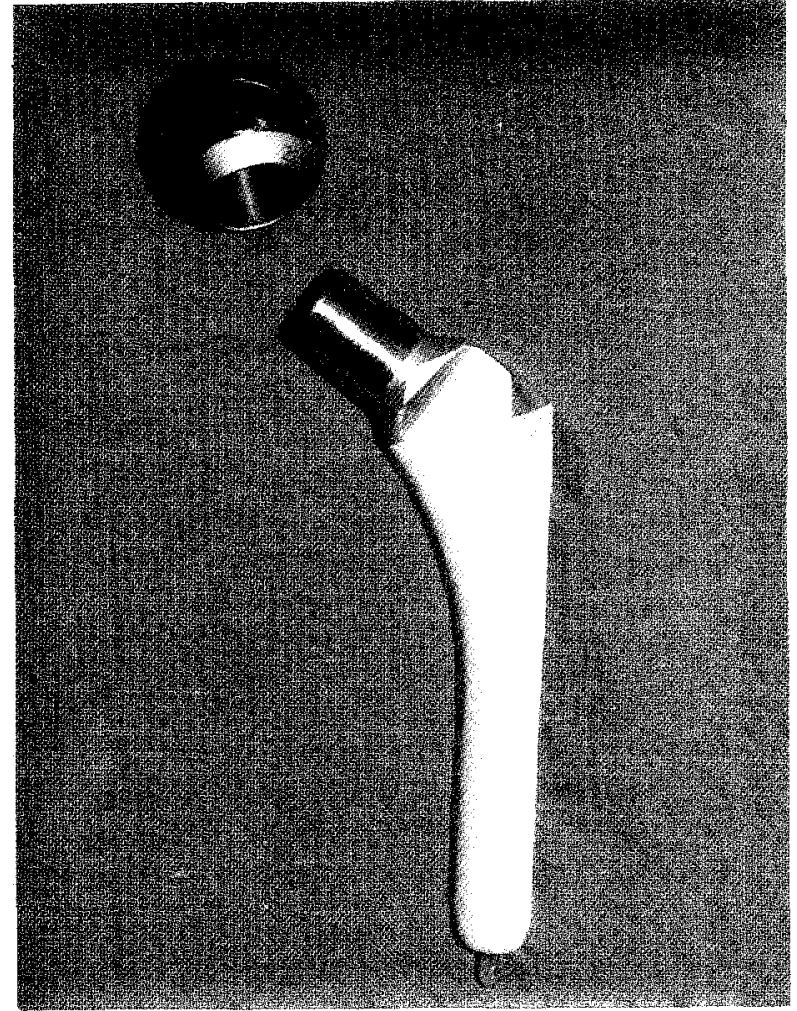

Fig. 2(b). The hydroxylapatite-coated titanium prosthesis.

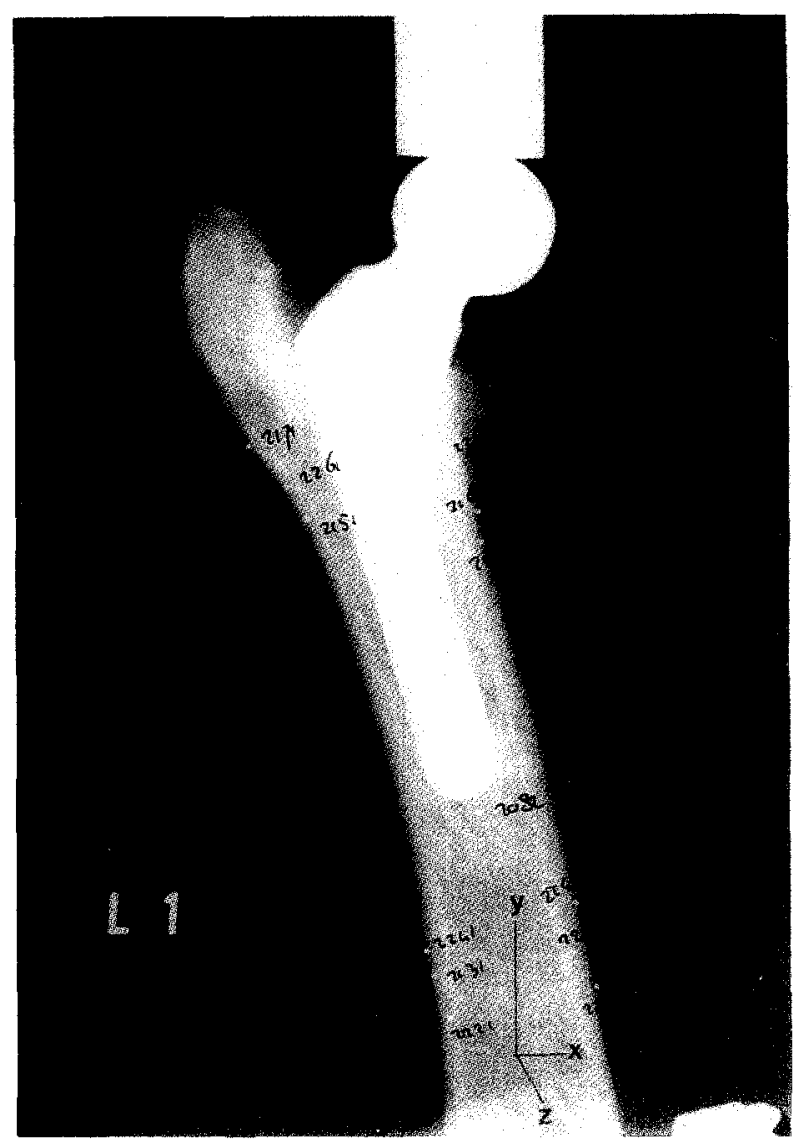

Hig. 3. Femur with bone grafts and a HA-coated prosthesis. The laboratory coordinate system is shown. 


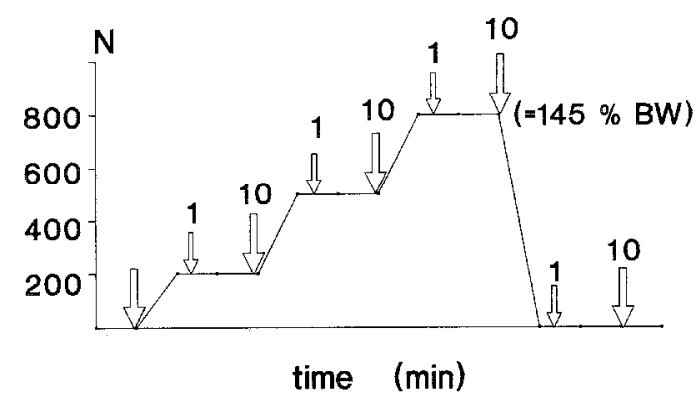

Fig. 4. The loading regime. Roentgenstereograms were made 1 and $10 \mathrm{~min}$ after each step in load. The arrows indicate when roentgenstereograms were taken.

\section{RESULTS}

The standard deviation for the translations was estimated at $0.036 \mathrm{~mm}$ and for the rotations at $0.07^{\circ}$, as determined by 5 independent measurements. The influence of the bone-pellet set combination selected was negligible. Only in the case of prosthesis CEM-4 was the deviation between the rotations determined with the different combinations of pellets larger $\left(0 \cdot 1^{\circ}\right)$ than the standard deviation.

In all loading steps very little difference was found for the displacements after 1 and $10 \mathrm{~min}$. In the presentation of results we limit ourselves to the displacements determined after 10 min.

In both the cemented and the non-cemented cases, the rotations around the medial-lateral $x$ axis in the sagittal plane, and the anterior-posterior $z$-axis in the frontal plane, were small (between $-0.5^{\circ}$ and $0.4^{\circ}$ ), except in one case (HAP-4, a frontal-plane rotation of $2.3^{\circ}$ ). In both prosthetic types, most rotation occurred around the axial $y$-axis (Fig. 5). The axial rotations increased with increasing load. The variations between the specimens were relatively high, but all showed the same trends. All stems, except CEM-3, rotated in the same (negative) direction. From zero to a load of $200 \mathrm{~N}, \mathrm{CEM}-3$ rotated $0.3^{\circ}$ in the positive direction, but for increasing loads again in the same direction as the others. Only one of the four cemented stems (CEM-2) produced axial rotations of real substance (up to $2 \cdot 1^{\circ}$ ); those of the other three did not reach beyond $0 \cdot 4^{\circ}$. The axial rotations of the non-cemented stems were much larger, maximally $2 \cdot 3-6 \cdot 8^{\circ}$ (Fig. 5). After subsequent unloading, the major part of these rotations proved to be permanent. Some elastic recovery was evident in both types of specimens, but was more pronounced in the cemented stems.

The maximal displacements of the cemented prostheses at the distal tip in the medio-lateral
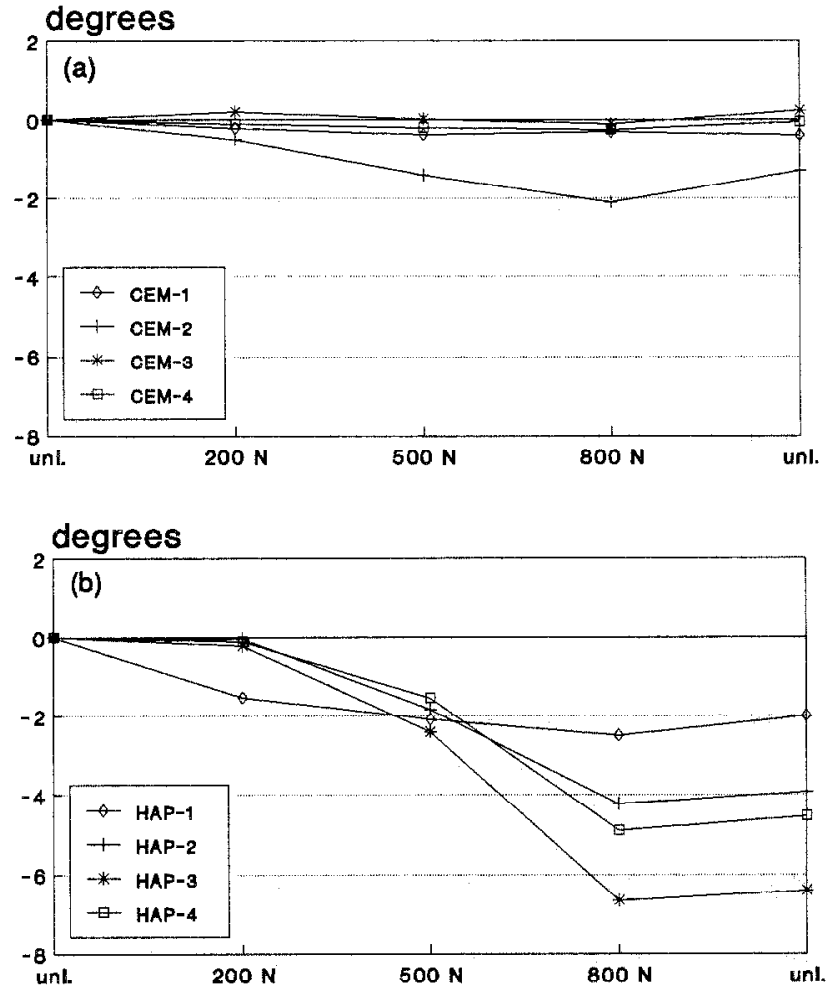

Fig. 5. Axial rotations found for (a) the cemented and (b) the non-cemented prostheses, from the unloaded case to stepwise increases of load, and again unloaded.

$x$ - and antero-posterior $z$-directions were only $0 \cdot 15$ $\mathrm{mm}$. In the non-cemented cases these translations were between 0.07 and $0.77 \mathrm{~mm}$, with one exception (HAP-4, translation in lateral direction of $1.71 \mathrm{~mm}$ ). In both cases the highest translations occurred in the axial $y$-direction (Fig. 6), resulting in subsidence of the prosthesis relative to bone. These translations followed similar patterns to the axial rotations. They also increased with increasing load. CEM-2 again displayed the highest amount of subsidence of the cemented stems, about $0.5 \mathrm{~mm}$ maximally. The subsidence of the other stems was much less. The non-cemented stems subsided much more, maximally about $1 \cdot 1-2.9 \mathrm{~mm}$ (Fig. 6). After unloading there was again some elastic recovery of the subsidence in both the cemented and the non-cemented cases, but most of the displacement was permanent. For both translations and rotations under loads of $500 \mathrm{~N}$, $800 \mathrm{~N}$ and again unloaded, the results were significantly different in the two types of prosthesis (Student's $t$-test, $P=0 \cdot 05$ ).

Translations were also calculated for the proximal/medial and proximal/lateral base points of the prosthesis. Interpretation of these results is difficult. These base points are located at some distance $(0.5-1.0 \mathrm{~cm})$ from the prosthetic axis. Therefore, the translations in the $x$ - and 

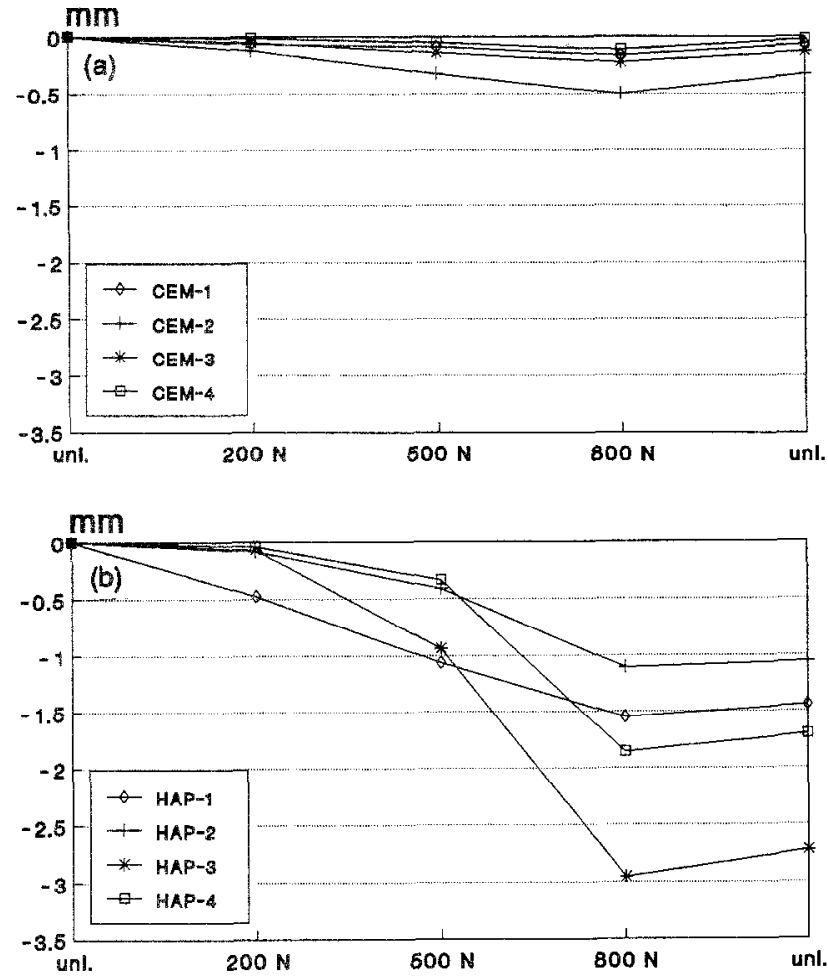

Fig. 6. Subsidence found for (a) the cemented and (b) the noncemented prostheses, from the unloaded case to stepwise increases of load, and again unloaded.

$z$-directions in particular are magnified by prosthetic rotations. Generally, it was found that the displacements in the $y$-direction were of the same magnitude for all three base points, with one exception (HAP-4), owing to its large distal displacement of $1.71 \mathrm{~mm}$ in the lateral direction.

\section{DISCUSSION}

The use of intramedullary femoral bone grafts in revision cases has been described earlier, ${ }^{9,14}$ although not in the impacted form used here. Nelson et al. ${ }^{15}$ presented three cases using femoral allografts in revision of hip replacement with noncemented stems. A preliminary report using a trial femoral component for impaction of cancellous bone grafts in cemented total hip arthroplasty was presented by Simon et al. ${ }^{16}$ Recently, Gie et $a l^{17}$ reported the results of impacted cancellous allografts for revision surgery with bone cement in cases with femoral bone stock loss in 56 hips with promising short-term results. However, there are no histological or mechanical data in the literature about the behaviour of these grafts.

The femur of the goat has a very hard and smooth endosteal surface, similar to the sclerotic bone often seen endosteally during revision surgery. The femur contains trabecular bone only in the proximal part. By using hand reamers, only this trabecular bone in the proximal femur was removed, the influence of the reaming technique on the hard cortical bone being limited. Although some biological variation in bone shape may be inevitable in experiments like this, the dimensions of the intramedullary canal are clearly controlled by the grafting technique.

The standard deviations measured are within the range described by Karrholm $^{18}$ for RSA accuracy (SD translations $0.010 .25 \mathrm{~mm}, \mathrm{SD}$ rotations $0.03-0.60^{\circ}$ ). By using the RSA method, only tantalum balls have to be placed in the test specimens, which is a relatively simple procedure relative to other methods. ${ }^{19-21}$ RSA produces a complete and very accurate three-dimensional reconstruction of the relative displacements of the prosthesis. Of course, the evaluation method is tedious and the RSA system must be available.

The force on the femoral head represented the direction and point of application of the maximal force in the sheep, as reported by Bergmann et $a .^{13}$ This load produces axial, torsional and bending components, which are considered important in testing the stability of stems. ${ }^{19,21,22}$ Bergmann et al. ${ }^{13}$ found maximal forces of $110 \%$ of body weight. The average weight of the goats we used was $55.3 \mathrm{~kg}$, so the maximal force of 800 $\mathrm{N}(144 \%$ of body weight $)$ seems to be sufficient.

This new technique of bone grafting was evaluated with a cemented and a non-cemented prosthesis. The components cannot simply be compared. The dimensions of the intramedullary space are defined by the grafting technique. Because the cementation technique requires space, the dimensions of the cemented prosthesis will always differ from the non-cemented prosthesis. In addition, the cemented stem had a collar, in contrast to the non-cemented stem. However, this collar never rested on the calcar but fits within the diameter of the femoral canal. In the literature we found no data for the initial stability of stcms fixated in combination with bone grafts. However, the results can be compared with literature data concerning the stability of stems fixated in primary THA. Schneider $e t a l .^{19}$ reported that subsidence and axial rotation occur predominantly in both cemented and non-cemented prostheses, although definitely less in the cemented ones. We found the same trends.

The better initial stability of the cemented stems is probably due to penetration of cement in the 
graft. In non-cemented cases the graft construction can definitely not provide enough initial stability, resulting in substantial subsidence and axial rotation in all cases. In the cemented cases, only one stem was initially unstable. The displacements for both types of prosthesis were predominantly non-elastic, hence permanent, owing to slippage and compaction of grafts. The courses of the curves suggest that forces of more than $800 \mathrm{~N}$ would have produced additional displacements for the four non-cemented and one cemented stem. Hence, it is unlikely that the stems had yet found stable positions. The excessive motions of prosthesis HAP-4, seen both proximally and distally (in the medio-lateral direction), were the result of an insufficient distal grafting techniquc. This was evident from X-rays.

\section{CONCLUSIONS}

A technique has been developed for severe femoral bone stock loss met in revision surgery of failed total hip arthroplasties using impacted trabecular bone grafts. In a loading experiment, subsidence and axial rotations were the most important relative displacements. The initial stability was better in the cemented cases than in the noncemented cases, because of cement penetration within the graft. It is possible that secondary stability is obtained after initial subsidence, when the stems found stable seatings.

\section{ACKNOWLEDGEMENTS}

This study was partially supported by Orthopedic Technology BV, The Netherlands, and Stryker Europe BV, The Netherlands. We should like to thank Ton Bijlaart, Huub Peeters and Willem van de Wijdeven for their assistance during the experiments and Dr A.J. Lemmens (Department of Radiology) for providing radiological techniques.

\section{REFERENCES}

1. Ahnfelt, L., Herberts, P., Malchau, H. \& Anderson, G.B.J., Prognosis of total hip replacements. Acta Orthop. Scand., 61 (1990) suppl. 238.
2. Slooff, T.J. \& Lindner, K., Extraction set. Acta Orthop. Scand., 45 (1974) 220-4.

3. Eftckhar, N.S., Rechannelization of cemented femur using a guide and drill system. Clin. Orthop., 123 (1977) 29-31.

4. Harris, W.H. \& Oh, I., A new power tool for removal of methylmethacrylate in failed total hip arthroplasties. Clin. Orthop., 132 (1978) 53-4.

5. McGann, W., Mankin, H.J. \& Harris, W.H., Massive allografting for severe failed total hip replacement. J. Bone $J t$ Surg., 68A (1986) 1-12.

6. Head, W.C., Berklachic, F.M., Malinnin, T.I. \& Emerson, R.H., Freeze-dried proximal femur allografts in revision total hip arthroplasty. Clin. Orthop., 225 (1987) 22-36.

7. Oakeshott, R.D., Morgan, D.A.F., Zukor, D.J., Rudan, J.F., Brooks, P.J. \& Gross, A.E., Revision total hip arthroplasty with osseous allograft reconstruction. Clin. Orthop., 225 (1987) 37-61.

8. Borja, F.J. \& Mnaymneh, W., Bone allografts in salvage of difficult hip arthroplasties. Clin. Orthop., 197 (1985) 12330 .

9. Wagner, H., Revisionsprothese für das Hüftgelenk bei schwerem Knochenverlust. Orthopäde, 16 (1987) 295-300.

10. Slooff, T.J., Huiskes, R., van Horn, J. \& Lemmens, A.J., Bone grafting in total hip replacement for acetabular protrusion. Acta Orthop. Scand., 55 (1984) 593-6.

11. Selvik, G., A roentgen-stereophotogrammetric method for the study of the kinematics of the skeletal system. Thesis, University of Lund, Sweden, 1974.

12. de Groot, K., Geesink, R., Klein, C.P.A.T. \& Serakian, P., Plasma sprayed coatings of hydroxylapatite. J. Biomed. Mater. Res., 21 (1987) 1375-81.

13. Bergmann, G., Siraky, J. \& Rohlmann, A., A comparison of hip joint forces in sheep, dog and man. J. Biomech., 17 (1984) 907-21.

14. Tyer, H.D.D., Huchstep, R.L. \& Stalley, P.D., Intraluminal autograft restoration of the upper femur in failed total hip arthroplasty. Clin. Orthop., 224 (1987) 26-32.

15. Nelson, I.W., Bulstrode, C.J.K. \& Mowat, A.G., Femoral allografts in the revision of hip replacement. $J$. Bone $J t$ Surg., 72B (1990) 151-2.

16. Simon, J.P., Fowler, J.L., Gie, G.A., Ling, R.S.M. \& Timperly, A.J., Impaction cancellous grafting of the femur in cemented total revision arthroplasty. J. Bone Jt Surg., 73B (1991) S73

17. Gie, G.A., Linder, L., Ling, R.S.M., Simon, J.P., Slooff, T.J.J.H. \& Timperley, A.J., Impacted cancellous allografts and cement for revision total hip arthroplasty. $J$. Bone $J t$ Surg., 75B (1993) 14-21.

18. Karrholm, J., Roentgen stereophotogrammetry. Acta Orthop. Scand., 60 (1989) 491-503.

19. Schneider, E., Eulenberger, J., Steiner, W., Wyder, D., Friedman, R J \& Perren, SM., Fxperimental method for the in vitro testing on the initial stability of cementless hip prostheses. J. Biomech., 22 (1989) 735-44.

20. Walker, P.S., Schneeweis, D., Murphy, S. \& Nelson, P., Strains and micromotion of press-fit femoral stem prostheses. .J. Biomech., 20 (1987) 693-702.

21. Burke, D.W., O'Connor, D., Zalenski, E.B., Jasty, M. \& Harris, W.H., Micromotion of cemented and uncemented femoral components. J. Bone Jt Surg., 73B (1991) 33-7.

22. Mjoberg, B., Hansen, L.I. \& Selvik, G., Instability of total hip prostheses at rotational stress. Acta Orthop. Scand, 55 (1984) 504-6. 